\title{
Macht den Kindern Beine! Was täglicher Schulsport bewirkt
}

Täglicher Schulsport im Grundschulalter senkt nicht nur den peripheren Blutdruck, sondern verbessert auch den zentralen Blutdruck und die Pulswellengeschwindigkeit. Das zeigt eine Interventionsstudie aus Berlin, die bei der Jahrestagung der Hochdruckliga vorgestellt wurde.

Die Sportmediziner um Dr. Sascha Ketelhut von der Universität Halle-Wittenberg führten eine clusterrandomisierte Studie durch, bei der zwei Schulklassen mit 24 bzw. 22 Schülern zwischen 6 und 7 Jahren verglichen wurden. Die eine Klasse absolvierte den normalen Berliner Schulsportunterricht, in diesem Alter drei Un- terrichtsstunden pro Woche unter Anleitung eines Hortbetreuers. Die andere Klasse hatte an den beiden sportfreien Schultagen zusätzlich jeweils 45 Minuten Bewegungstraining unter Aufsicht eines ausgebildeten Übungsleiters.

\section{Kreislaufparameter verbessert}

Nach neun Monaten zeigten sich zwischen den beiden Gruppen deutliche, oft statistisch signifikante Unterschiede hinsichtlich der mit dem Deutschen Motorik-Test (DMT 6-18) ermittelten motorischen Fähigkeiten. So stieg die Laufleistung bei einem 6-Minuten-Lauf in der Interventionsgruppe von im Mittel rund 800 auf über 900 Meter, während sich in der Kontrollgruppe nichts änderte. Und der motorische Gesamt-Score im DMT nahm in der Interventionsgruppe hoch signifikant stärker zu.

Auch bei praktisch allen Kreislaufparametern schnitt die Interventionsgruppe besser ab. Der periphere Blutdruck sank von 112/67 mmHg auf 110/65 $\mathrm{mmHg}$, während er in der Kontrollgruppe zunahm. Der zentrale Blutdruck sank von 98/69 $\mathrm{mmHg}$ auf 97/67 $\mathrm{mmHg}$, und die Pulswellengeschwindigkeit sank von $4,5 \mathrm{~m} / \mathrm{s}$ auf $4,4 \mathrm{~m} / \mathrm{s}$. Auch bei diesen $\mathrm{Pa}$ rametern gingen die Veränderungen in der Kontrollgruppe jeweils in die andere Richtung.

(Philipp Grätzel)

40. Wissenschaftlicher Kongress der Deutschen

Hochdruckliga, Dezember 2016, Berlin

\section{Hier steht eine Anzeige.}

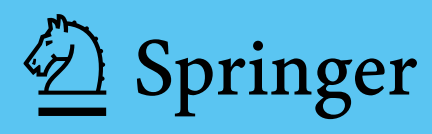

